\title{
A política monetária e a crise financeira: podem os Bancos Centrais se antecipar? *
}

\author{
Marcelo Milan *** \\ Bernardo Cordenonzi de Quadros ***
}

\begin{abstract}
Resumo
Este trabalho investiga o comportamento dos bancos centrais $(\mathrm{BCs})$ dos EUA e do Brasil frente à recente crise financeira global. $\mathrm{O}$ artigo avalia a atuação das autoridades monetárias por meio de uma leitura sistemática das atas dos respectivos comitês de política monetária entre 2004 e 2011. Procura também identificar conceitos necessários para uma correta leitura e reconhecimento da conjuntura macroeconômica e logo uma possível antecipação ou reação adequada à eclosão da crise. Em ambos os casos os BCs não parecem ter sido capazes de diagnosticar corretamente a evolução da conjuntura macroeconômica, principalmente em termos de detectar a bolha no setor imobiliário dos EUA e se antecipar ao estouro da mesma quando esta adquiriu proporções preocupantes. Quando os mercados financeiros entraram em pânico, os BCs tiveram de reagir pragmaticamente de reagir, mas de forma desorganizada, emergencial e, possivelmente, despreparada, em função da complexidade dos sistemas monetário e financeiro e provavelmente dos respectivos interesses financeiros envolvidos. Finalmente, argumenta-se também que parte desta incapacidade de antecipação pode derivar, entre outros, dos modelos macroeconômicos convencionais empregados pelos BCs e de uma confiança absoluta na hipótese dos mercados eficientes.
\end{abstract}

Palavras-chave: Banco Central; Política monetária; Crise financeira; Defasagens; Macroeconomia.

\begin{abstract}
Monetary policy and the financial crisis: could Central Banks have anticipated the crisis?

This study investigates the behavior of US and Brazilian central banks (CBs) regarding the recent global financial crisis. The article evaluates their conduct through a systematic review of the minutes from the respective committees' meetings between 2004 and 2011. The key concepts necessary to carry out a proper review were employed, in addition to an awareness of the macroeconomic conjuncture and therefore the ability to anticipate or properly react to the crisis. In both cases, the CBs do not seem to have been able to diagnose the evolution of the macroeconomic environment correctly, mainly in terms of detecting the bubble in the US housing sector, and even to anticipate the bubble bursting when it reached worrying levels. When financial markets panicked, both CBs had to react pragmatically, but in a disorganized way and with haste. They were also possibly unprepared, given the complexity of financial and monetary systems, and the financial interests behind it. Finally, it argues that the inability to anticipate could be found, in part, in the use of conventional macroeconomic models used by the CBs and in the blind faith in the efficient market hypothesis.
\end{abstract}

Keywords: Central Banking; Monetary policy; Financial crisis; Lags; Macroeconomics. JEL E58, H12, E44, E65.

* Artigo recebido em 25 de julho de 2014 e aprovado em 22 de janeiro de 2016

** Professor do Departamento de Economia e Relações Internacionais e dos Programas de Pós-Graduação em Economia e em Estudos Estratégicos Internacionais da Universidade Federal do Rio Grande do Sul (UFRGS), Porto Alegre, RS, Brasil. E-mail: marcelo.milan@ufrgs.br.

*** Mestrando em Análise Econômica pela Universidade Carlos III, Madri, ES. E-mail: bernardo_cq@hotmail.com. 


\section{Introdução}

Este artigo investiga a capacidade de antecipação dos bancos centrais (BCs) frente a episódios de crises financeiras, tomando como experimento a crise financeira global de 2007-2008, a mais profunda crise desde a Grande Depressão (OCDE, 2009). Esta capacidade é importante em razão do argumento de que existem defasagens entre a decisão sobre mudanças nos instrumentos de política monetária e os efeitos sobre a economia (Kelton, 2006). Blinder (2004) discute os argumentos tradicionais, postulados por Friedman (1948 e 1960) de que a política fiscal tem uma longa defasagem interna (reconhecimento, decisão e implementação), mas apresenta efeitos imediatos após implementada (isto é, uma defasagem externa curta). Já a política monetária teria uma defasagem interna mais curta e uma defasagem externa (impacto) mais longa. Por outro lado, Carlin e Soskice (2005) mostram que no novo consenso macroeconômico (NCM), as expectativas são formadas de forma a antecipar o futuro (forward-looking). Neste sentido, é importante avaliar o tempo necessário para um BC diagnosticar corretamente a existência de bolhas nos mercados de ativos em um contexto de reduzidas medidas de prevenção à formação das mesmas ${ }^{1}$. Igualmente relevante é o tempo exigido para a autoridade monetária reagir ao colapso de uma bolha e estabilizar os mercados financeiros, assumindo que o laissez-faire é impraticável no mundo real e mais ainda no contexto de uma crise financeira ${ }^{2}$. O tempo de reação da economia a estas políticas, por outro lado, se situa fora do escopo deste trabalho.

Assim, o artigo procura entender se os BCs podem se antecipar a episódios de crise em um contexto de crescente instabilidade financeira, diagnosticando-os corretamente e adotando as medidas apropriadas a partir de uma determinada fundamentação macroeconômica. Para tanto, a questão a ser respondida é: em que medida a crise recente corrobora a existência de uma curta defasagem interna, principalmente a fase de diagnóstico e reconhecimento dos problemas, na implementação da política monetária? Para respondê-la, o artigo apresenta as interpretações da conjuntura macroeconômica feitas pelo FED e pelo Bacen entre 2004 e 2011, considerando um intervalo que se estende de três anos antes da eclosão da crise em 2007 até três anos após o seu aprofundamento e transformação em uma crise global em 2008. O intervalo de três anos é arbitrário, mas suficiente para tratar as questões de antecipação e reação discutidas no texto. Além disso, o artigo avalia

(1) Blanchard (2011) mostra que o consenso no mainstream antes da crise era de que a política monetária deveria ter como único objetivo a estabilização dos preços por meio de mudanças na taxa de juros (um objetivo, um instrumento). Alan Greenspan, ex-presidente do FED, foi um incansável defensor da desregulamentação dos mercados financeiros e monetários (Milan, 2012).

(2) A falência do banco Lehman Brothers em setembro de 2008 sugere que as tentativas de implementação de políticas de laissez-faire não funcionam em períodos de graves perturbações financeiras. Estas tentativas, generalizadas nos anos 1980 e 1990, provavelmente contribuiram para a crescente instabilidade financeira que redundou na eclosão de muitas crises (Bresser-Pereira, 2010). 
as reações dos mesmos ao estouro da bolha e à crise que se seguiu, e finalmente, o grau de adesão destas interpretações aos acontecimentos que se seguiram. A escolha destes dois BCs se justifica pela possibilidade de avaliar o comportamento de duas organizações operando em economias com distintas estruturas econômicas, regras de política monetária, instituições e posições na hierarquia da economia mundial. Até onde foi possível perceber, não há estudos adotando tal abordagem de forma sistemática, para o período de tempo considerado. Com isso, há potencial de contribuição original na temática em discussão.

A análise se centra na interpretação da conjuntura macroeconômica, em particular do mercado imobiliário e suas interconexões financeiras, feita pelo FED e pelo Bacen antes e durante o estouro da bolha do subprime e a eclosão da crise. Estes aspectos são considerados em termos das previsões teóricas sobre o papel da política monetária na prevenção e, ausente esta, na reação durante períodos de crises financeiras derivadas de bolhas no mercado de ativos. Com relação às possibilidades de atuação dos BCs frente a bolhas e crises, as perspectivas teóricas do mainstream e heterodoxas são examinadas. Quanto ao diagnóstico dos BCs sobre a conjuntura pré-crise, sua evolução e desdobramento em recessão, foi realizada uma leitura sistemática das atas dos respectivos comitês de política monetária para o período de 2004 a 2011, empregando uma metodologia adotada também por Bullio et al. (2011) e Ferrara e Carvalho (2014). Este método é similar às análises das discussões feitas 'por trás de portas fechadas', seguindo Kelton $(2006)^{3}$, e do discurso do banco mundial de Moretti e Presque (2015). Constitui-se igualmente em um estudo de caso, abordagem defendida por Mishkin (2007) ${ }^{4}$. A presença dos principais conceitos associados às crises nos documentos é então quantificada e tabulada. Trata-se de um procedimento simples, que pode não captar totalmente a orientação dos BCs, o grau de entendimento sobre a formação da bolha ou mesmo a intenção das ações de política monetária implementadas antes e durante a crise. Porém, esta metodologia fornece uma primeira aproximação ao complexo processo envolvido na operacionalização da política monetária nos períodos imediatamente anteriores à crise, no auge do pânico e no período de propagação da crise do sistema financeiro para o setor real.

Os resultados obtidos sugerem que os BCs não foram capazes de diagnosticar corretamente, e logo de se antecipar à formação da bolha e ao estouro

(3) Kelton não discute a atuação do FED frente a crises. Ela discute as mudanças nos objetivos e procedimentos do FED durante os anos 1990 (publicação das minutas, divulgação da meta para a taxa de juros e o viés da mesma) e em que medida as mesmas refletem transformações na economia (aumentos de produtividade proporcionados pela "nova economia") ou na teoria macroeconômica mainstream ("novo consenso" sintetizado na Regra de Taylor). Segundo a autora, a abordagem permite entender as motivações do FED de forma direta, sem a necessidade de inferi-las a partir das políticas adotadas.

(4) $\mathrm{O}$ autor relata a resistência acadêmica a esta abordagem em estudos monetários, mas defende seu emprego em função da capacidade de identificação de choques e de detalhes sobre diferentes políticas monetárias. 
da mesma, e em alguns casos tomaram decisões contraproducentes frente ao cenário macroeconômico prospectivo, meramente reagindo de forma desordenada às consequências do colapso da bolha. Uma explicação plausível, como discutido sucintamente adiante, é que esta dificuldade de se antecipar pode ser entendida pela própria fundamentação teórica em que se baseia a implementação da política monetária atual, em modelos de equilíbrio geral estocástico e dinâmico (DSGE) sem qualquer papel relevante para o setor financeiro, ou na fé cega na capacidade autorreguladora dos mercados financeiros, expressa na hipótese dos mercados eficientes. Outras explanações são contempladas brevemente.

O artigo está organizado da seguinte forma: Após esta introdução, o trabalho discute brevemente algumas perspectivas mainstream e as heterodoxas sobre a possibilidade de antecipação da política monetária em episódios de crise e a reação à crise, além da questão das defasagens. Na próxima seção os resultados quantitativos e qualitativos, encontrados a partir da leitura das atas dos comitês de política monetária, são apresentados e discutidos. A última seção conclui o trabalho.

\section{Bolhas em preços de ativos, defasagens e política monetária: abordagens teóricas}

A questão de se um BC pode se antecipar a bolhas financeiras por meio de instrumentos monetários e regulatórios, ou reagir ao decorrente colapso financeiro por meio da política monetária, exige a discussão de se a antecipação e a reação se justificam e se são possíveis com base nas teorias econômicas. Este é o objeto das próximas duas próximas subseções. A questão especificamente da defasagem é tratada na última subseção.

\subsection{Perspectivas do mainstream}

A abordagem mainstream não é homogênea. Sem exaurir a discussão das diferenças, esta subseção discute algumas perspectivas representativas reunidas em Hunter et al. $(2005)^{5}$ e outros estudos recentes. Nesta seleção, ao contrário dos modelos de equilíbrio geral dinâmico e estocástico (DSGE), o setor financeiro importa. Duas visões sobre o papel da política monetária diante de uma bolha no preço de ativos podem ser identificadas na corrente mainstream mais ampla: uma contra a inclusão dos preços dos ativos na "função de reação" do BC ("negligência benigna'), e outra a favor ('remar contra o vento') ${ }^{6}$. Nas abordagens selecionadas,

(5) Tymoigne (2009) e Bullio et al. (2011) discutem outros trabalhos que tratam do mesmo assunto.

(6) As divergências não se limitam a episódios de crise. Kelton (2006) mostra a divisão no FED sobre um aumento na taxa de juros em 1999, quando os aumentos na produtividade elevaram o crescimento e o nível de emprego sem afetar a inflação. Parte dos membros do FOMC era a favor da elevação com base em relatórios técnicos empregando a regra de Taylor, e outros preferiam esperar para ver se a inflação iria mesmo aumentar, o que não ocorreu. 
em geral os preços dos ativos financeiros são considerados importantes na medida em que afetam a estabilidade econômica, entendida como estabilidade do produto e dos preços.

Mishkin e White (2005) enfatizam o efeito riqueza na transmissão de choques dos mercados de ações, acompanhado de mudanças no custo de capital, para a economia real. Um BC que otimize a conduta da política monetária deve reagir a eles. Os autores questionam se a política monetária deveria reagir à volatilidade das ações apenas quando esta ultrapassa os níveis que afetariam a economia. Eles se baseiam em um estudo segundo o qual os BCs devem reagir em tempo aos preços das ações a fim de parar bolhas antes que elas fiquem fora de controle. Sobre a reação das autoridades monetárias a um crash, Mishkin e White defendem uma política monetária fortemente expansionista em função do estresse provocado pelas dificuldades financeiras experimentadas por bancos e outras instituições. Eles analisam 15 episódios de crise e concluem que o principal problema não é o crash ou o estouro da bolha, mas as dificuldades financeiras que se seguem. Assim, os BCs deveriam ter foco na estabilidade financeira, possibilitando melhor resposta frente às flutuações do mercado.

Da mesma forma, Ito (2005) discute como os preços dos ativos podem ameaçar a estabilidade de preços por meio do efeito riqueza, com aumentos no consumo e no investimento sem resposta do lado da oferta, e quedas no preço dos ativos reduzindo o dispêndio e os preços. Assim, defende uma política agressiva de injeção de liquidez como reação a casos de danos potenciais à estabilidade financeira, mas não considera a introdução dos preços dos ativos na função de reação do BC. Ito destaca a importância da supervisão e regulamentação para manter a estabilidade financeira e evitar volatilidade em excesso. Portanto, a autoridade monetária deve intervir preventivamente e, no caso de falhas, reativamente por meio do emprestador de última instância.

Já Friedman (2005) discute se os preços de ativos possuem informações que podem ser úteis, isto é, relacionadas aos objetivos da política monetária. Em caso positivo, elas podem ser exploradas pelos formuladores da política, não importa se os preços são corretos ou não. $\mathrm{O}$ autor questiona se há espaço para os preços dos ativos nos modelos macroeconômicos e afirma que o problema é essencialmente empírico.

Mussa (2005) defende que os preços dos ativos são variáveis macroeconômicas relevantes e seus comportamentos trazem implicações para os objetivos da política monetária, pois são indicadores do desempenho futuro dos preços e do nível de atividade. $\mathrm{O}$ autor afirma que em algumas circunstâncias os preços dos ativos deveriam exercer influência sobre a conduta da política monetária, quando estes têm variações especulativas, por exemplo. Porém, é necessário cautela 
no uso desses preços na formulação da política, já que a supressão da volatilidade da maioria dos preços de ativos não é viável nem desejável.

Para Trichet (2005), os preços dos ativos financeiros, além de colocarem em risco a estabilidade de preços, objetivo exclusivo de muitos $\mathrm{BCs}$, podem ainda afetar a estabilidade financeira, já que ocasionalmente a dinâmica dos preços dos ativos se descola da atividade econômica, com a ocorrência de movimentos especulativos. Contudo, o procedimento operacional de fixação da taxa de juros com base na volatilidade financeira exige cuidado, em função da incerteza sobre estes preços e da dificuldade em se mensurar o valor fundamental dos ativos sobre o qual desvios seriam calculados para determinar a forma de intervenção ${ }^{7}$. Assim, parte das oscilações nos preços de ativos é devida ao comportamento de agentes que simplesmente emulam os grandes investidores. A prevenção deve ser feita com base em três medidas: 1) aumento da transparência (a falta de informação é um fator determinante no comportamento imitativo dos agentes $)^{8}$; 2) criação de regras e normas adaptadas aos horizontes de médio e longo prazo de alguns participantes (fundos de pensão, por exemplo, investem com o objetivo de construir riqueza a médio ou longo prazo, mas às vezes são pressionados a olhar para o curto prazo); e 3) diversificação dos instrumentos de controle de risco (as instituições financeiras geralmente utilizam as mesmas técnicas de apuração de risco e tendem a ter comportamentos parecidos).

Borio e Lowe (2005) argumentam que as oscilações cíclicas nos preços dos ativos aparecem em muitos episódios de volatilidade excessiva e crises financeiras. Os autores localizam as causas das elevações nos preços dos ativos na rápida expansão do crédito. A maior probabilidade de problemas para o sistema financeiro se dá quando surge uma combinação simultânea de rápido crescimento do crédito e dos preços dos ativos, com repercussões reais. Eles afirmam que a questão mais relevante para os formuladores de políticas é quando uma bolha expõe o sistema financeiro a um grande grau de risco. Os autores defendem a importância de políticas tanto no sentido prudencial, perante riscos financeiros potenciais, quanto no sentido de reação a possíveis desequilíbrios no mercado financeiro, defendendo a cooperação entre as diferentes autoridades econômicas tanto para o gerenciamento

(7) Esta posição é questionável no caso da bolha no mercado imobiliário norte-americano, avaliada em US\$ 8 trilhões no período de pico, um valor facilmente identificável. A bolha por definição não se forma já no valor de pico, mas de forma gradativa e cumulativa por um período de tempo que vai muito além do imediato (Baker, 2009).

(8) Esta perspectiva é compatível com a abordagem Keynesiana sobre o emprego de convenções para neutralizar a incerteza intrínseca em decisões cujos resultados acontecem no futuro. Por outro lado, o argumento levanta a questão de porque os agentes adotariam estratégias de investimento distintas a partir da posse da mesma nova informação disponível, principalmente sobre o valor esperado da variável no futuro. Isto é, as transações financeiras refletem expectativas distintas sobre o futuro, que continua sendo incerto, não importa quanta informação o BC torne pública. 
das crises como para evitar o aparecimento das mesmas. Isto requer fortalecer a estrutura regulamentadora e prudencial e a capacidade de resposta da política monetária a desequilíbrios financeiros que redundem em depressão e deflação.

Adicionalmente, os autores rejeitam as objeções ao uso da política monetária como resposta a bolhas: a identificação, em um estágio inicial, de desequilíbrios financeiros que garantam uma margem confortável para implementar as medidas, o risco de desestabilizar a economia em função da imprevisibilidade dos efeitos da política e a necessidade de justificar a resposta ao público. Para Borio e Lowe estes argumentos ficam aquém de excluir uma resposta da política monetária. Isto porque, por exemplo, as objeções superestimam a dificuldade de identificar desequilíbrios financeiros. Eles argumentam que as regras de política monetária devem estar atentas para o fato de que desequilíbrios no sistema financeiro podem ocorrer mesmo em conjunturas de baixa inflação ou desinflação, por diversas razões. É importante notar que, embora os autores reconheçam a importância da estabilidade financeira, eles a veem como um subproduto da estabilidade de preços propriamente definida.

Cecchetti, Genberg e Wadhwani (2005) defendem que os preços dos ativos não devem ser parte da política monetária, nem na função objetivo do BC nem na medida de inflação adotada como meta pelo BC. Porém, acreditam que a reação dos BCs a desalinhamentos nos preços dos ativos, para além da estabilidade de preços e hiato do produto nas regras de Taylor, podem melhorar o desempenho e a estabilidade macroeconômica. Os motivos são as distorções criadas por esses desalinhamentos sobre o consumo e o investimento. Essa reação a desalinhamentos nos preços dos ativos seria feita por meio das taxas de juros, elevando-as moderadamente quando os preços dos ativos sofrem um aumento além do que é justificado, e reduzindo-as moderadamente quando eles ficam abaixo de certos níveis. Compensa-se, assim, os efeitos das bolhas sobre o produto e a inflação.

Os autores se baseiam no trabalho de Bernanke e Gertler (1999) para corroborar o argumento de que a política monetária deve responder a mudanças nos preços dos ativos apenas quando os mesmos sinalizem mudanças na inflação esperada, nos marcos de um regime flexível de metas de inflação. O trabalho de Bernanke e Gertler é importante em um outro aspecto fundamental. Os autores mostram que crises financeiras geram impacto negativo sobre o produto apenas quando a política monetária permanece sem resposta aos efeitos deflacionários das crises, mas que políticas agressivas de metas de inflação, ignorando o preço dos ativos, são efetivas em reduzir a ocorrência de uma crise financeira sem outros prejuízos macroeconômicos. Portanto, a negligência da evolução financeira pela política monetária é fundamentalmente benigna nos marcos do regime de metas em um dos poucos modelos DSGE com papel para distúrbios financeiros. Esta visão da 'negligência benigna' aos preços dos ativos, todavia, é rejeitada por Bordo e Jeanne (2002), para quem uma simples regra de política do tipo considerada no regime de 
metas não permite abarcar todas as situações em que reversões nos preços financeiros podem ter consequências importantes para a economia. A política monetária deve ser preventiva.

Goodfriend (2005), embora argumente que os preços dos ativos desempenhem indiretamente um papel importante para a política monetária nas previsões de demanda agregada e inflação, também é contra a reação direta da política monetária aos preços dos ativos na determinação da taxa de juros. Para ele, um aperto monetário em um panorama de aumento das expectativas inflacionárias faz o preço dos ativos cair devido à elevação das taxas nominais e reais de longo prazo e à deficiência de demanda agregada. Referindo-se aos preços das ações, Goodfriend argumenta que essa queda na demanda causa um declínio nos lucros presentes e futuros das empresas. Esse fato, aliado à maior taxa de juros usada para trazer a valor presente os lucros futuros, faz com que os investidores precifiquem para baixo o preço as ações. Em épocas de inflação estabilizada, se o BC reduz as taxas de juros para estimular o consumo, ocorre o inverso, ou seja, os preços das ações tendem a subir, respondendo assim a maiores expectativas de lucros e menores taxas de juros no desconto dos lucros futuros. Dessa forma, o BC não deve se antecipar às bolhas.

Adicionalmente, Goodfriend tenta explicar como as taxas de juros e os preços de ativos se relacionam com diferentes combinações de choques de demanda e de oferta. Existem três situações em que os preços dos ativos podem enganar a política monetária: medo da inflação, compressão de lucros e aumentos na tendência de crescimento da produtividade. Essas três situações, em que, diante de um choque de oferta, seria mais apropriado para as autoridades monetárias moverem as taxas de juros em sentido oposto ao movimento dos preços dos ativos, sustentam o argumento de que a política monetária não deveria reagir diretamente a esses preços.

Finalmente, uma perspectiva mainstream escrita no período após a eclosão da crise de 2007-2008 é proporcionada pelo relatório Rethinking Central Banking, da Brookings Institution (Eichengreen et al., 2011). O relatório argumenta que as autoridades monetárias, ao invés de tentar identificar bolhas que estão acontecendo junto a um rápido crescimento do crédito ou outros indicadores de excesso financeiro, devem estar atentas se as condições financeiras aumentam a probabilidade de reversões nos preços de ativos que seriam prejudiciais à atividade econômica. O uso de testes de estresse é recomendado para medir os impactos de mudanças no crédito. O relatório reafirma a importância da estabilidade financeira, argumentando que esta deveria se tornar um objetivo explícito dos BCs, podendo ser perseguida principalmente por meio de medidas macroprudenciais, como mecanismo explícito de estabilização macrofinanceira. Estas devem ter como objetivo a identificação de acúmulos de riscos à estabilidade financeira, e como instrumentos as exigências anticíclicas de capital e os controles de capital, não a taxa 
de juros. Neste caso, a estabilidade de preços deixaria de ser o objetivo exclusivo dos BCs e o regime de metas de inflação caracterizado por um objetivo, um instrumento deveria ser flexibilizado. Ainda segundo o relatório, as medidas macroprudenciais ajudam a atenuar transbordamentos de instituições individuais ao sistema financeiro, considerando que obrigações e haveres interrelacionados criam externalidades quando a falência de uma instituição alavancada ameaça a solvência de outras instituições e a estabilidade agregada. Vendas emergenciais de ativos podem amplificar choques e levar a uma espiral deflacionária e desalavancagem. Externalidades também podem surgir se as exigências de capital são pró-cíclicas.

\subsection{Perspectivas heterodoxas}

Borio (2012) argumenta que o ciclo de crédito e o papel das finanças na teoria macroeconômica foram abandonados pelo mainstream ${ }^{9}$ e discutidos por autores como Minsky e Kindleberger. Para além destas contribuições seminais, em geral os aspectos mais específicos da relação entre BC, política monetária e bolhas em preços de ativos e crises financeiras não têm recebido um tratamento frequente na literatura heterodoxa. Palley (2006) sugere, por exemplo, que a contribuição póskeynesiana sobre a política monetária ainda é limitada. De fato, um influente livro pós-keynesiano (Rousseas, 1998) trata da política monetária e do processo de criação endógena de moeda, mas não discute a relação entre política monetária e crises financeiras. Arestis e Sawyer (1998) organizaram estudos sobre vários aspectos da economia política e credibilidade dos BCs, mas sem uma discussão acerca da ocorrência frequente de crises financeiras no capitalismo e como a autoridade monetária poderia evitá-las ou minimizar seus efeitos. Mais recentemente, Gnos e Rochon (2009) apresentam discussões sobre governança econômica, política macroeconômica, metas de inflação e independência dos BCs, mas não bolhas e crises.

Esta produção heterodoxa relativamente exígua sobre a capacidade de antecipação dos BCs a bolhas de ativos e crises financeiras não é surpreendente, já que a instabilidade financeira, quando transmitida ao setor real, tem apenas seus

(9) Em suas palavras (Borio, 2012, p. 1, 23): "The notion of the financial cycle, and its role in macroeconomics, is no exception. (...). But for most of the postwar period it fell out of favour. It featured, more or less prominently, only in the accounts of economists outside the mainstream (eg, Minsky, 1982 e Kindleberger, 2000). Indeed, financial factors in general progressively disappeared from macroeconomists' radar screen. Finance came to be seen effectively as a veil - a factor that, as a first approximation, could be ignored when seeking to understand business fluctuations (eg, Woodford, 2003). And when included at all, it would at most enhance the persistence of the impact of economic shocks that buffet the economy, delaying slightly its natural return to the steady state (eg, Bernanke et al, 1999). (...) Modelling the financial cycle raises major analytical challenges for prevailing paradigms. It calls for booms that do not just precede but generate subsequent busts, for the explicit treatment of disequilibrium debt and capital stock overhangs during the busts, and for a clear distinction between non-inflationary and sustainable output, ie, a richer notion of potential output - all features outside the mainstream." 
efeitos, e não suas causas, combatidos geralmente por meio da defesa do uso da política fiscal. De fato, Minsky $(1975,1979,1982,1985,2008)$ argumenta que a instabilidade intrínseca do capitalismo deriva de estruturas financeiras. Ou seja, o problema vai além da existência de episódios de bolhas nos preços de ativos. Quando a instabilidade financeira se processa na forma de crises, a política monetária desempenha um papel relevante, com o BC (big bank) reagindo como emprestador de última instância e os déficits fiscais do governo central (big government) estabilizando a demanda efetiva. Assim, não há uma extensa literatura sobre a efetividade de mecanismos ex ante ou de prevenção às crises, seja por meio de instrumentos de política monetária, seja por meio de regulação, pois aquelas são inevitáveis em uma economia capitalista. Por outro lado, há maior convergência em torno dos instrumentos necessários para gerenciá-la ex post. Novamente, nesta perspectiva o BC não pode se antecipar, dada a incerteza fundamental postulada por Keynes, mas sua atuação é fundamental para evitar que uma recessão se aprofunde e se transforme em uma depressão. Além do ceticismo de Minsky, a existência de incerteza fundamental lança dúvidas sobre a capacidade dos BCs se anteciparem de forma precisa, ainda que medidas prudenciais para regulamentar o sistema financeiro sejam defendidas (Tymoigne, 2009).

Em um dos poucos trabalhos a tratar do assunto, Palley (2011) considera que a tendência recente de repensar o BC e seu papel na prevenção de bolhas tem duas vertentes. A primeira é composta daqueles economistas operando dentro das instituições e aceitando o status quo. Neste caso, a opção é por melhorar a supervisão bancária e evitar bolhas em ativos, nos moldes do mainstream. A segunda inclui aqueles economistas trabalhando fora dos BCs e do mainstream da profissão e a quem caberia a discussão sobre governança e independência, reformas no arcabouço de metas inflacionárias e a introdução de reservas baseadas em ativos. O autor afirma que as propostas internas e externas divergem em termos da teoria macroeconômica por trás das mesmas, com as primeiras assumindo a visão mainstream e as segundas uma interpretação pós-keynesiana.

Propostas mais recentes que tratam da instabilidade financeira incluem Tymoigne (2009). O autor defende a criação de uma Comissão de Resolução e Supervisão Financeira para estabilizar o sistema financeiro. Neste caso o BC não executaria uma política monetária de estabilização do nível de preços e da atividade econômica, mas uma política sistemática de estabilidade financeira, investigando posições de risco e avaliando a introdução de inovações financeiras. O autor rejeita a centralidade da estabilidade de preços e da necessidade de se manter um regime de metas de inflação. Especificamente, políticas anti-inflacionárias não deveriam ser conduzidas pelo BC, mas por outros órgãos do governo, já que a inflação não tem apenas origens monetárias. Palley (2003, 2011) adota uma visão parecida, defendendo o uso de reservas lastreadas em ativos, não em passivos, para controlar 
bolhas nos preços dos ativos. Estas perspectivas invertem as proposições do mainstream, já que não há medidas de estabilização financeira subordinadas à estabilidade de preços ${ }^{10}$.

A contribuição heterodoxa reside em grande parte na crítica ao mainstream. Assim, segundo a perspectiva heterodoxa, um elemento que contribui para a dificuldade dos BCs atuarem de forma mais decisiva na prevenção e tratamento das crises parece residir no arcabouço teórico empregado por estas instituições. Dullien (2012), avaliando a política fiscal e não a política monetária, mostra que os modelos DSGE não geram melhores previsões e sugestões de política que os tradicionais modelos IS-LM-CP ou IS-LM-BP. Por sua vez, ao se considerar que, segundo Borio (2012), os modelos DSGE em geral não possuem mercados financeiros que os aproximem do mundo real, no caso da política monetária, uma possível incapacidade de efetuar uma leitura correta da conjuntura e se antecipar à crise não deveria, portanto, ser surpreendente. A relativa estabilidade financeira alcançada no pósguerra nos países desenvolvidos foi resultado de mecanismos regulatórios fundamentados na visão de que mercados financeiros são inerentemente instáveis. E no contexto de economias financeirizadas, a instabilidade financeira ampliada é potencialmente estimulada pelo funcionamento do regime de metas de inflação, em que a estabilidade financeira, quando considerada, ficaria subordinada à estabilidade de preços. Assim, como visão geral, a estabilização financeira decorre de medidas preventivas e da utilização da política monetária para transferir liquidez da esfera financeira para a esfera industrial.

Por fim, a rápida recuperação da renda e da riqueza da classe capitalista nos EUA com a política monetária de facilitação quantitativa após o colapso patrimonial em 2007-2008, sugere que outros aspectos de economia política e dos interesses financeiros devam ser incorporados na análise do funcionamento do BC para entender a operacionalização da política monetária, como sugere Epstein (1992 e 2002). Papadatos (2012) analisa a política monetária estruturada pelo regime de metas de inflação e o papel do BC nesta estrutura. $\mathrm{O}$ autor argumenta que as seguidas crises financeiras nos anos 1990 ampliaram o escopo de atuação do BC e levaram a uma crescente contestação da estabilidade de preços como objetivo exclusivo da política monetária. Os estudos sobre o regime de metas de inflação não seriam conclusivos a respeito dos impactos macroeconômicos do mesmo, com desempenho parecido entre os países que adotaram o regime e aqueles que não o fizeram. Papadatos discute o contexto histórico do regime de metas e explica as transformações na política monetária e das funções do BC a partir da hegemonia das finanças desde os anos 1970. O autor rejeita a teoria do "território contestado" do

(10) Palley (2006) defende a introdução do regime de metas de inflação em um arcabouço pós-keynesiano como mecanismo para operacionalizar o nível de fixação da taxa de juros, mas não subsume a busca pela estabilidade financeira a este arcabouço. 
BC enquanto arena de disputas intra- e interclasse, apontando para transformações ocorridas no mercado de trabalho, no conflito capital-trabalho e no conflito indústriafinanças a partir das mudanças tecnológicas e políticas ocorridas no período. Com estas mudanças, o BC passa então a defender os interesses dos rentistas acima de outros objetivos, sendo o regime de metas um instrumento para realizá-lo.

Com relação às crises financeiras, Papadatos rejeita a hipótese de que a estabilidade de preços seria suficiente para garantir a estabilidade financeira. A ocorrência de inflação no preço dos ativos e bolhas financeiras a partir da difusão do regime de metas de inflação e independência dos BCs levanta dúvidas sobre esta associação. Nos países desenvolvidos, a financeirização conduziu a bolhas nos preços de ativos, que ocorreram em um contexto de baixa inflação, gerando argumentos favoráveis à flexibilização do regime de metas de inflação para garantir medidas emergenciais no caso de crises. $\mathrm{O}$ autor considera difícil identificar bolhas no início de sua formação, pois inovações tecnológicas que elevam a produtividade conduzem também à formação de bolhas. E existe a crença, por parte de muitos banqueiros centrais, de que seria melhor deixar a bolha estourar e remediar os custos com a ampliação da liquidez (negligência benigna). Papadatos argumenta que esta é uma política típica de socialização dos prejuízos quando o BC atua em favor dos interesses rentistas, o que torna a prevenção de crises menos importante. A eclosão de bolhas aponta para os problemas com o regime de metas de inflação e do aumento de importância das funções de emprestador de última instância e mesmo de "formador de mercado" de última instância para ativos privados em um contexto de pânico financeiro. Por outro lado, o autor aponta para dinâmicas autônomas do sistema de crédito que limitam a atuação dos BCs na prevenção e tratamento das crises e para a necessidade de mudanças no controle social da política monetária.

\subsection{A questão das defasagens}

A discussão das defasagens também pode ser diferenciada em termos das abordagens teóricas de economia política. Do lado mainstream, Friedman (1948) foi um dos primeiros a abordar as defasagens, principalmente em termos da política fiscal. Para o autor, as defasagens são longas e variáveis, o que eleva o grau de incerteza sobre os resultados das políticas anticíclicas e pode torná-las desestabilizadoras. Portanto, políticas discrecionárias devem ser evitadas em favor de arranjos automáticos ou regras simples, como uma meta para o nível de preços. $\mathrm{O}$ autor divide a defasagem total das políticas econômicas em três partes: (1) Entre a necessidade de ação e o reconhecimento de tal necessidade (o que Blinder chama de defasagem interna); (2) entre o reconhecimento da necessidade e a tomada de decisão (também parte da defasagem interna); e (3) entre a ação e seus efeitos (defasagem externa segundo Blinder). Friedman considera que a primeira parte poderia até ser negativa se a previsão for acurada, mas que é melhor fundamentar a 
ação em uma análise da conjuntura. Friedman (1960) aborda as defasagens da política monetária e afirma que a parte (3) da defasagem é igualmente longa e variável. Postula então regras contra ação discricionária dos BCs. Friedman ignora, nestas obras, possivelmente pelo fato de existir uma forte regulamentação à época, o papel negativo que o setor financeiro pode desempenhar nas flutuações cíclicas da economia. E o fato de os BCs seguirem regras de política monetária como a regra de Taylor pode ocasionar crises e bolhas, contribuindo para desestabilizar a economia por adotar medidas mais próximas às demandadas por Friedman.

Os textos do mainstream discutidos na subseção anterior não direcionam a discussão neste sentido, mas é possível, a partir das análises, chegar-se a uma posição quanto às defasagens. Mishkin e White (2005) consideram a ação preventiva do BC, mas uma ação preventiva requer diagnóstico correto e logo que as defasagens internas sejam reduzidas, e portanto o BC deve se antecipar e presume-se que ele também possa se antecipar, reduzindo a defasagem interna. Da mesma forma, para Ito (2005), o BC pode se antecipar por meio de instrumentos prudenciais. Friedman (2005) é mais ambíguo sobre estas possibilidades. Para Mussa (2005), as políticas monetárias possuem um caráter tanto de prevenção, o que sugere uma defasagem interna reduzida, como de reação às possíveis crises que ocorrem devido ao colapso nos preços dos ativos, com defasagem interna reduzida. Para o autor, a questão não é 'como a política monetária deveria se ajustar aos preços dos ativos', e sim 'quando ela deveria se ajustar'. Para ele, baseando-se apenas nos preços de ativos é difícil determinar o momento exato em que a política monetária deveria reagir aos excessos do mercado financeiro, o que levanta dúvidas sobre a curta defasagem interna à política monetária e sobre a capacidade de antecipação dos BCs. Trichet defende que as autoridades monetárias trabalhem preventivamente para aumentar a diversidade de comportamentos no mercado financeiro. Neste caso o BC pode e deve se antecipar à ocorrência de distúrbios financeiros, mas com instrumentos prudenciais, reduzindo a defasagem interna.

Já a importância dada por Borio e Lowe (2005) para o crédito na determinação dos preços dos ativos reforça que a regulação pode ter um papel na prevenção de possíveis problemas financeiros e que a política monetária deve reagir quando da eclosão da crise. Portanto, o BC pode e deve se antecipar, mas por meio de ações conjuntas com outras instituições. A prevenção é uma antecipação que torna a defasagem interna mais curta, pois impede a formação de distúrbios em primeiro lugar. Para Cecchetti, Genberg e Wadhwani (2005), os BCs devem tanto se antecipar como reagir a evoluções nos mercados financeiros por meio da taxa de juros, mas apenas quando há distorções no consumo e no investimento com repercussões sobre os preços. Com base no trabalho de Bernanke e Gertler (1999), defendem um regime de metas de inflação flexível, o que tenderia a eliminar excessos nos mercados financeiros e tornar a reação do $\mathrm{BC}$ redundante, pois a operação da política monetária 
tornaria as crises menos factíveis. A própria melhoria institucional tornaria a defasagem interna mais curta. Bordo e Jeanne (2002) argumentam, contudo, que a política monetária deve ser preventiva e ir além do regime de metas, o que exige defasagem interna reduzida, mas de outra natureza. Para Goodfriend (2005), o BC não deve se antecipar nem reagir, mesmo que possa, em função das dificuldades envolvidas em identificar a combinação de choques de oferta e demanda na economia para então calibrar a política monetária, ou seja, uma defasagem interna longa torna a política monetária inefetiva, nos moldes de Friedman. Para a Brookings Institution o BC pode se antecipar se possuir funções de supervisão e monitoramento do sistema financeiro, reduzindo a defasagem interna, e adotar um regime de metas mais flexível para considerar a estabilidade financeira, mas não por movimentos nas taxas de juros.

Em resumo, as perspectivas selecionadas do mainstream sugerem duas perspectivas claras: uma que assume existir uma defasagem interna reduzida, e que os BCs possam se antecipar a eventos financeiros, mesmo que não devam. E outra que assume ser difícil identificar uma bolha em formação, isto é, a defasagem interna é longa, mas um compromisso com a estabilidade de preços seria suficiente para evitar crises financeiras. A prevenção seria não intencional. Há também papel para supervisão e regulação financeira atuando de forma preventiva pelo BC ou outra instituição, e um papel para a política monetária em estabilizar o sistema financeiro após uma crise, com uma defasagem externa relativamente curta no que tange à injeção de liquidez no sistema financeiro pós-colapso.

Da perspectiva heterodoxa, os trabalhos de Palley $(2003,2011)$ e Tymoigne (2009) sugerem que, na medida em que o BC pode se antecipar, é na forma de medidas de regulação financeira, não de política monetária, também reduzindo a defasagem interna. De forma mais geral, a própria dificuldade analítica de tratar o setor financeiro nos modelos do mainstream, ao mesmo tempo em que se defende o aprofundamento da desregulamentação e liberalização financeiras, aponta para a necessidade de recorrência das bolhas e crises. $\mathrm{O}$ aumento da instabilidade contribui para a própria ampliação da defasagem interna. Por fim, para Papadatos, o BC não pode se antecipar, o que sugere uma ampla defasagem interna. Mas o BC reage às crises como mecanismo de manutenção da renda e riqueza dos segmentos rentistas, fazendo com que os efeitos de crise recaiam sobre as demais classes e frações de classes, reduzindo a defasagem externa de forma extremamente rápida para a fração rentista e também para os trabalhadores, mas de forma negativa.

Ainda nesta perspectiva, e considerando a questão de forma explícita, Sicsú (1999), ainda que não tratando da atuação do BC frente a uma crise, discute o problema das defasagens. $\mathrm{O}$ autor argumenta que, dentro de certas condições de normalidade Marshalliana, em que o comportamento médio é o comportamento esperado de certos grupos de agentes, durante um período de tempo também 
considerado normal, o BC pode se antecipar a eventos futuros e evitar o problema das defasagens internas. Contudo, é difícil conceber uma economia capitalista, caracterizada por inovações e busca incessante pelo lucro, como sugerido por Papadatos, como sendo caracterizada pelo conceito Marshalliano de normalidade. E mesmo se este fosse o caso, Minsky (op. cit.) sugere que a estabilidade, que seria característica de um período de normalidade, é desestabilizadora. Da mesma forma, a crítica não valida a visão mainstream acerca das longas defasagens internas e do papel potencialmente desestabilizador da política monetária. De acordo com Minsky, o BC, na função de emprestador de última instância, junto ao Tesouro, estabilizam temporariamente o capitalismo. Desta forma, a eventual incapacidade do $\mathrm{BC}$ em se antecipar a crises e atuar de forma estabilizadora, derivada da instabilidade sistêmica sob a qual opera, pode ser minimizada por períodos curtos de tempo, dentro de um ambiente institucional em que a estabilidade financeira seja um objetivo explícito do $\mathrm{BC}$ e outras agências do Estado.

Este argumento sobre a dificuldade enfrentada pelos BCs em atuarem com base em expectativas sobre eventos futuros e logo de se antecipar é ilustrado por Bain e Howells (2003). Os autores apresentam um evento, não relacionado a crises financeiras, em que o FED adotou posições ambíguas. Em novembro de 2000 a instituição assumia um risco mais elevado de inflação, mas em dezembro do mesmo ano o risco havia se deslocado para a desaceleração da economia, sem que a taxa de juros fosse modificada. Em janeiro de 2001, poucos dias após o encontro anterior, houve então uma reunião extraordinária e uma redução na taxa de juros. Da mesma forma, Kelton (2006) mostra como o FED decidiu elevar as taxas de juros a partir da reação desproporcional do setor financeiro à divulgação do viés de alta pelo banco, dada uma elevação esporádica no núcleo da inflação em $1999^{11}$. Da mesma forma, como mostra a discussão na próxima seção, o comportamento do FED e do Bacen na crise recente reforça esta característica. Neste caso, o BC se guia fundamentalmente pelo passado recente para tomar decisões, dificultando sua capacidade de se antecipar aos eventos ${ }^{12}$. Ou seja, em termos da teoria Keynesiana, a incerteza fundamental afeta o processo decisório dos BCs, com suas ações derivando de um comportamento convencional que simplesmente projeta o passado recente para o futuro. Ou ainda uma situação de autonomia meramente parcial do $\mathrm{BC}$, em que a atuação do mesmo reflete a pressão dos mercados financeiros, estando sujeita, portanto, a episódios de moda e comportamento de manada (Kelton, 2006).

(11) Kelton (2006) mostra também como as anedotas são importantes na tomada de decisão do FED e como muitas vezes as decisões contrariam as próprias orientações da instituição: por exemplo, assumir que a estabilidade de preços foi alcançada e mesmo assim aprovar uma elevação na taxa de juros - o que sugere a importância de se entender a economia política dos bancos centrais. Na mesma linha, Ritholtz (2014) destaca o aumento no número de risos nas transcrições das atas do FOMC até um pico em junho de 2007.

(12) Este comportamento do BC levanta dúvidas sobre a abordagem das expectativas racionais, a qual fundamentaria a formação de expectativas futuras por parte de agentes e instituições. 
Neste caso, agir preventivamente se torna mais difícil e a defasagem interna é alongada. E durante episódios de crise financeira, em que todas as convenções e projeções se tornam menos confiáveis, o BC fica sem parâmetros de atuação e adota o pragmatismo (Bullio et al., 2011). Esta condição é ainda reforçada pela orientação recente dos BCs em tentar estabilizar apenas os níveis de preços. A próxima seção apresenta evidências mais sistemáticas a respeito desta dificuldade.

\section{A atuação dos Bancos Centrais dos EUA e do Brasil frente à crise}

Esta seção ilustra as percepções que as autoridades monetárias tinham sobre a elevação de preços dos ativos imobiliários nos Estados Unidos e se as mesmas permitem caracterizar a defasagem interna à política monetária como relativamente rápida, isto é, como sugerindo uma capacidade de antecipação por parte dos BCs a partir de um diagnóstico correto. Adicionalmente, a seção avalia as reações aos desdobramentos da eclosão da crise. Para isso, são analisadas as atas das reuniões do Federal Open Market Committee (FOMC) e Comitê de Política Monetária (Copom).

\subsection{Análise qualitativa das Atas do Comitê Federal de Mercado Aberto (FOMC)}

Ao longo de 2004, o FOMC percebeu o aquecimento no setor imobiliário. A ata da reunião de janeiro sustenta que a atividade no mercado imobiliário seguia robusta. $\mathrm{Na}$ ata da reunião de março, o FED citou relatórios que sugeriam um crescimento especulativo dos preços em algumas regiões, conduzindo-os a um nível acima do que seria consistente com os fundamentos. Citou-se na mesma ata que alguns membros do comitê estavam preocupados com as políticas de estímulo monetário por meio de taxas reduzidas de juros, pois elas poderiam intensificar o aumento da alavancagem e a tomada de riscos excessivos, além de aumentar a chance de instabilidade financeira quando a política se tornasse restritiva. Apesar disso, a meta para a taxa de juros foi mantida em $1 \%$ ao ano em função da inflação baixa e do mercado de trabalho sem pressões. Já o FED possui um mandato legal dual de estabilizar os preços, mas sem uma meta explícita, e também o de manter baixas taxas de desemprego. Assim, existia a suspeita do problema. O FED elevou as taxas de juros gradualmente até meados de 2006. Como a crise irrompeu em 2007, gerando uma recessão ao final daquele ano, esta elevação, a única medida em três anos tomada pelo FED, se mostrou inefetiva em reverter o aumento nos preços dos imóveis. Como o aumento nas taxas pode refletir também um receio de inflação, é preciso entender o que aconteceu neste intervalo de tempo.

$\mathrm{A}$ ata de setembro destacou o aumento do número de pedidos de hipotecas. Ao final do ano a atividade no setor imobiliário continuava forte, com vendas próximas de níveis recordes, em função de taxas de juros reduzidas. Na reunião de dezembro de 2004, assim como na de março do mesmo ano, alguns participantes 
também demonstraram preocupação com a liquidez excessiva, com spreads muito baixos, que possibilitava a tomada excessiva de riscos, mencionando também demandas especulativas em determinados nichos do mercado imobiliário. Outro aspecto sugerido em dezembro foi que os preços dos imóveis teriam efeitos no consumo das famílias por meio do efeito riqueza. Esse efeito, aliado à possibilidade de aumento na taxa de juros de longo prazo, foram destacados novamente na ata da reunião de fevereiro de 2005, assim como os riscos de queda no consumo das famílias, alimentado por refinanciamentos e empréstimos garantidos pelos imóveis, e a desaceleração na construção de moradias.

Durante todo o ano de 2005, os preços dos imóveis seguiram aumentando, embora diminuindo o ritmo de crescimento no final do ano. O FOMC indicou na reunião de maio de 2005 que existiam sinais de processos especulativos excessivos no mercado imobiliário em algumas áreas. Na ata da reunião de junho, o comitê destacou a rápida valorização no setor imobiliário em termos de renda e aluguéis, consequência dos aumentos da renda disponível, baixas taxas de juros e das inovações financeiras no mercado de hipotecas. O comitê reconheceu que embora os preços pudessem estar sobrevalorizados, mesmo considerando esses fatores, seria difícil, por questões conceituais e estatísticas, mensurar essa sobrevalorização. Na mesma reunião, os participantes observaram o aumento de empréstimos hipotecários mais arriscados do ponto de vista do crédito. Mas reafirmaram a confiança de que em geral as instituições financeiras permaneciam em posição confortável, devido ao bom desempenho dos empréstimos até aquele momento, às transferências de riscos pela securitização e ao aumento do valor dos imóveis acima da dívida das hipotecas. Assim, o comitê observou a evolução dos empréstimos para agentes com alto risco de crédito, mas não viu isso como sendo um problema para as instituições financeiras naquele momento, que era simplesmente o auge da bolha.

Um importante relato sobre o papel da política monetária em resposta a possíveis desequilíbrios no mercado imobiliário e de títulos foi feito na ata da reunião de junho de 2005. Para os participantes, a política monetária deveria levar em consideração os preços dos ativos somente na medida em que eles ameaçassem os objetivos de política monetária, estabilidade de preços e crescimento econômico sustentável, em conformidade com a visão de Bernanke e Gertler (1999). Isso porque haveria muitas incertezas envolvidas no julgamento dos preços dos ativos, corroborando Goodfriend (2005). Assim, uma estratégia de política monetária que respondesse sempre a esses preços dificilmente contribuiria para a realização dos objetivos da política. De fato, para Bernanke, que viria a se tornar presidente do FED quatro meses depois, em outubro de 2005 a evolução dos preços dos ativos imobiliários não caracterizava uma bolha, mas refletiam os fortes fundamentos econômicos dos EUA: "But these increases, he [Bernanke] said, 'largely reflect 
strong economic fundamentals,' such as strong growth in jobs, incomes and the number of new households." (Henderson, 2005). Assim, sem um diagnóstico correto da conjuntura, a capacidade de antecipação se torna irrelevante. Por outro lado, na reunião de dezembro, os participantes começaram a discutir os primeiros sinais de que a atividade no setor imobiliário estava começando a desacelerar, mas os dados não mostravam um enfraquecimento significativo, sem qualquer menção à bolha. Nota-se, assim, que o FOMC, em particular o presidente do FED, não conseguiu detectar uma bolha de US\$ 8 trilhões que acontecia no preço dos imóveis (Baker, $2009)^{13}$.

O ano de 2006 foi marcado por um arrefecimento no mercado imobiliário norte-americano, com uma desaceleração no crescimento dos níveis de preços dos imóveis no início do ano e uma queda no final do ano. Esse declínio foi discutido na ata da reunião de março de 2006. Para o comitê, uma desaceleração nos preços das residências poderia levar a um menor crescimento do consumo das famílias e da demanda agregada. Mas o comitê não via a desaceleração no setor de construção como significativa. $\mathrm{Na}$ ata de maio, o FOMC alertou para 'os produtos não tradicionais de hipoteca' e seu potencial de trazer dificuldades financeiras para as famílias e para os credores. A queda no crescimento do consumo das famílias aconteceu no segundo trimestre do ano. O comitê apontou entre os motivos os aumentos no preço da energia, a redução da apreciação dos preços de imóveis e o aumento das taxas de juros, e não o processo de reversão da bolha.

Em agosto de 2006, o comitê ainda não via deterioração nas condições financeiras das famílias em termos de pedidos de falência e taxas de inadimplência. $\mathrm{Na}$ ata de setembro, o FOMC afirmou que a contração na construção de imóveis estava amortecendo a expansão econômica dos EUA. A construção e as vendas de residências tinham diminuído e as taxas de juros para hipotecas tinham aumentado, enquanto o aumento no preço dos imóveis no segundo trimestre de 2006 tinha se dado em taxas muito baixas comparativamente com o que tinham crescido até então. Na última reunião de 2006 o comitê continuou observando a desaceleração no setor imobiliário, com um menor ritmo de construção e declínios nos preços residenciais, sem adotar nenhuma medida com relação a estes eventos.

O ano de 2007, da deflagração da crise e início da recessão segundo o NBER, começou com o FOMC avaliando que a chance de uma contração maior no setor habitacional tinha diminuído e que os impactos sobre o crescimento seriam arrefecidos ao longo do ano. Na reunião de março de 2007, o comitê percebeu um

(13) Ferrara e Carvalho (2014) interpretam estas percepções de outra forma. Para os autores, o FED reconhecia a existência de uma bolha de ativos ou pelo menos de desequilíbrios entre os preços e os fundamentos, mas não considerava prudente intervir em função do papel que a elevação dos preços dos imóveis desempenhava na recuperação da economia dos choques sofridos no início da década. 
aumento na inadimplência em hipotecas subprime que tinham taxas de juros ajustáveis, ao mesmo tempo em que as taxas de juros aumentavam e o crédito diminuia. Porém, os participantes não viam sinais de que esse movimento passaria do segmento subprime para o mercado imobiliário como um todo. Na ata da reunião de maio, o comitê discutiu o efeito da inadimplência vista no setor de empréstimos subprime se propagar para o resto do mercado, afirmando que isso não havia acontecido. Na mesma ata foi notada uma desaceleração das vendas no setor imobiliário. Essa diminuição de preços levou a uma preocupação com a diminuição do consumo.

Em junho o comitê demonstrou preocupação com a inadimplência nas hipotecas de alto risco e seus efeitos para o mercado imobiliário, com o congelamento do crédito imobiliário e a queda na demanda por unidades habitacionais. Na reunião de agosto, nota-se o início da volatilidade no mercado financeiro. No período, o comitê notou uma fuga dos investidores para ativos seguros, em substituição aos ativos de maior risco, principalmente aqueles garantidos por empréstimos hipotecários. Muitos segmentos do mercado financeiro se deterioraram rapidamente. O crédito para emprestadores mais arriscados se tornou escasso, com rápida elevação dos spreads. Operações mais especulativas foram postergadas ou modificadas.

Nos dias após a reunião de agosto, as condições dos mercados financeiros pioraram e os empréstimos interbancários foram prejudicados. A ata da reunião de setembro discutiu os problemas nos mercados financeiros de curto prazo em função das exposições às hipotecas subprime e aos produtos estruturados de crédito. Debateu também as medidas de contenção do crédito a agentes expostos aos papéis lastreados em ativos como forma de os bancos manterem a própria liquidez. Como consequência, o mercado interbancário congelou e as taxas de juros aumentaram substancialmente. Isso levou o FED a tomar medidas que visavam o aumento de liquidez no sistema financeiro sob estresse, como o fornecimento de reservas por meio de operações de mercado aberto e de redesconto. Ou seja, tomaram-se medidas reativas, já que não se havia tomado medidas preventivas quando surgiram as primeiras evidências de problemas. A partir dessas evoluções, o comitê observou que os riscos para o crescimento econômico tinham aumentado e afirmou que estava preparado para mitigar possíveis efeitos adversos sobre a economia decorrente de disrupções no mercado financeiro. As políticas de rápida redução da taxa de juros, assim como a política de elevação entre 2004 e 2006, não parecem ter surtido efeito, já que o limite da taxa nominal zero foi atingido em 16 de dezembro de 2008 . O que parece ter contribuído para evitar uma catástrofe maior foi a socialização dos prejuízos e as operações de resgate de instituições financeiras, como argumenta Papadatos (2012). 
Cabe notar, a título de síntese, que a divulgação recente das transcrições completas das reuniões de 2007, que por lei só podem ser publicadas depois de 5 anos, mostram que mesmo em dezembro daquele ano o banco ainda se apegava à visão otimista de que apenas uma breve recessão ocorreria, o que se mostrou totalmente equivocado (Federal Reserve Board, 2013). Assim, embora os problemas não fossem completamente ignorados desde pelo menos 2004, nenhuma ação para evitar a expansão da bolha foi tomada além da elevação gradual da taxa de juros, até porque a própria bolha não foi identificada como tal, e quando a recessão se tornou efetiva, o FED acreditava que a desaceleração seria rápida e superficial. A adoção de políticas não convencionais de facilitação quantitativa nos últimos anos sugere que os efeitos foram duradouros, tornando ainda mais claros os erros de antecipação das autoridades no período pré-crise. Por outro lado, as medidas tomadas pelo FED, se não levaram a uma plena recuperação da economia, não foram incompatíveis com níveis recordes de lucro do setor financeiro nos EUA (Deutsche Bank, 2013), sugerindo de fato a existência de defasagens externas muito curtas.

\subsection{Análise qualitativa das Atas do Copom}

A discussão da análise da conjuntura feita pelo Copom deve ser qualificada pelo fato de a crise ter sido iniciada nos EUA. Dada a assimetria dos países na hierarquia da economia mundial, a dinâmica doméstica é importante para o Bacen, mas não é tão importante para a dinâmica mundial. Mesmo assim, é importante ver como a instituição analisou os desdobramentos do cenário externo durante o período, já que a taxa de câmbio e os fluxos de capitais são considerados pelo Copom em sua decisão de política. Ao longo do ano de 2004, o órgão via como favorável o ambiente econômico externo. $\mathrm{Na}$ ata da $94^{\mathrm{a}}$ reunião, em março, o Copom avaliava o cenário externo como positivo, com perspectivas de crescimento e alta liquidez internacional. Sobre a política monetária norte-americana, o comitê mostrava na última reunião de 2004 que não esperava um aumento abrupto da taxa de juros nos EUA, apenas aumentos graduais, o que de fato ocorreu, como usual. Durante o ano de 2005, o Copom supunha que a elevada liquidez internacional e a estabilidade nos mercados estavam condicionadas ao quadro macroeconômico dos EUA e às respostas do FED a esse quadro. Nesse sentido, o Copom continuava a atribuir baixa probabilidade de mudanças na política monetária norte-americana que criassem turbulência nos mercados financeiros. $\mathrm{Na} 112^{\mathrm{a}}$ reunião, em setembro, o comitê citava uma possível reversão no preço dos imóveis nos Estados Unidos como um risco à continuação do crescimento global, juntamente com o preço do petróleo. Mas não discute como esta leitura afetou as decisões de política monetária.

Na reunião de maio de 2006, diante do desaquecimento do mercado imobiliário norte-americano, ponderou-se que existia apenas um pequeno risco de diminuição do crescimento mundial e uma alta probabilidade de crescimento 
robusto. Em outubro de 2006, o comitê discutiu a possibilidade de um aperto monetário excessivo e uma possível recessão na economia dos Estados Unidos, que teria implicações potenciais para a economia brasileira, embora por alguns fatores, o Copom visse o país mais resistente aos choques externos em função da boa situação macroeconômica. Na mesma reunião o comitê afirmou que o ajuste no segmento imobiliário norte-americano estava ocorrendo de forma ordenada, com um sistema bancário sólido. Esta avaliação se mostrou, a posteriori, equivocada. A $123^{a}$ reunião também notava essa retração no mercado imobiliário e a desaceleração da demanda nos EUA.

O Copom iniciou o ano de 2007 reduzindo a meta para a taxa Selic para $13 \%$ ao ano, em um cenário internacional que para o comitê permanecia favorável, porém com novas fontes de incertezas. Diante disso, na ata de janeiro de 2007, afirmava-se que se os riscos eram exacerbados, o Bacen teria condições de responder de forma adequada. É importante notar que o comitê se propunha a adequar as estratégias de política monetária a situações em que a inflação seria prejudicada, não considerando outras variáveis, como a estabilidade financeira, seguindo estritamente as regras do regime de metas. Na reunião de março de 2007, o comitê afirmava que havia inquietação nos mercados financeiros globais com relação ao crescimento mundial e ao mercado subprime. Porém, esse panorama de volatilidade e de menor liquidez não se configurava em um quadro preocupante, assumindo que as causas eram transitórias e que a economia brasileira era robusta. Portanto, o cenário externo seguia sendo favorável. Apesar de mencionar uma menor liquidez, o comitê argumentava que não havia problemas. Por outro lado, em feveireiro de 2007 já se podiam notar sinais de crise, com perdas associadas aos empréstimos subprime (Cecchetti, 2008, p. 8).

Nas reuniões de abril e de maio, o comitê mostrava que havia incertezas a respeito da situação econômica e do rumo da política monetária nos EUA, com a possibilidade de uma desaceleração das economias norte-americana e mundial. Segundo o Copom, parte da desaceleração da economia norte-americana ocorria devido aos problemas no setor imobiliário. No que se refere aos desdobramentos para a economia brasileira, o comitê seguia afirmando que a economia e os preços dos ativos estavam bem alinhados com os fundamentos, apresentando resistência às mudanças de sentimento nos mercados financeiros. Com isso, apesar das incertezas, o Copom seguia considerando o cenário externo como favorável. Essas mesmas palavras foram encontradas também na ata da $127^{\mathrm{a}}$ reunião do Copom, realizada em junho de 2007, apenas seis meses antes da crise se aprofundar nos EUA.

Nesta última reunião o comitê também discutiu a avaliação do FMI a respeito da economia global. Para o fundo, embora os riscos de crescimento da economia mundial tivessem diminuído em razão do ajuste no segmento imobiliário 
nos EUA, os riscos financeiros tinham aumentado apenas modestamente, com pouco impacto potencial sobre a estabilidade financeira, o que também se mostrou equivocado. $\mathrm{Na}$ ata da reunião de julho, embora o comitê seguisse avaliando que o cenário externo continuava benigno, notava-se que havia riscos associados à correção no mercado imobiliário norte-americano, turbulências nos fundos hedge e uma possível contaminação dos mercados emergentes, mas não se discutiu o que fazer em caso de contágio. Após a reunião de julho, houve turbulências nos mercados financeiros internacionais, geradas pelo mercado imobiliário subprime, e isso é mostrado na ata da reunião do Copom de setembro, em que o comitê utilizou a palavra crise para se referir aos problemas no mercado de crédito e outros ativos financeiros. Nota-se também que houve uma mudança substancial na avaliação do cenário externo, considerado de alta volatilidade. Os BCs dos principais países passaram a injetar liquidez nos mercados financeiros por meio de operações de mercado aberto e de redesconto, desfazendo o quadro otimista pintado pelo comitê até então.

Sobre a futura conjuntura econômica, o comitê sugeria que as preocupações continuariam. Nesse aspecto, também foi afirmado na ata que havia a incerteza normal associada à conjuntura econômica e à resposta dos BCs. Reconhecia-se que a crise contagiaria o setor real da economia nos EUA, mas a economia mundial seria menos afetada. Ou seja, o comitê subestimava o contágio da crise e não previa grandes choques na economia mundial. E como fator agravante, em 2008 o Bacen elevou as taxas de juros em meio ao colapso dos mercados financeiros mundiais. No início de 2007 a meta para a taxa Selic estava fixada em 13,25\% ao ano, sendo reduzida até atingir 11,25\% em abril de 2008, quando a economia dos EUA já se encontrava em recessão. A partir de então a taxa aumentou até atingir 13,75\% em janeiro de 2009, quando voltou a cair. Portanto, enquanto a crise se agravava em setembro de 2008, a taxa básica de juros, já elevada para padrões internacionais, estava em meio a um período de elevação. Neste caso, o fato de a economia brasileira não ter sido impactada tanto quanto outras economias dificilmente pode ser atribuído à política monetária. E em que medida o regime de metas de inflação contribui para explicar este comportamento é uma questão a ser explorada em outro trabalho.

\subsection{Análise quantitativa das Atas do FOMC e do Copom}

As tabelas 1 e 2 a seguir mostram a frequência com que alguns termoschave, considerados centrais por este trabalho para identificar um quadro severo de instabilidade e crise como o que de fato caracterizou a economia mundial entre 2007 e 2009, aparecem nas atas dos comitês e comissões ${ }^{14}$. É importante notar que o

(14) As transcrições completas das reuniões do FED, como já mencionado, são disponibilizadas apenas com um atraso de cinco anos e não foram empregadas nesta análise, sendo mantida a análise das atas publicadas. 
número de reuniões não é o mesmo para o período anterior a 2006, ano em que o Copom passou a se reunir oito vezes ao ano, assim como o FED, que o faz desde 1981. Assim, faz mais sentido comparar a evolução para cada país separadamente. A frequência no uso dos termos mede, ainda que indiretamente, a importância destes conceitos no diagnóstico da conjuntura feito pelos membros que decidem sobre as ações dos $\mathrm{BCs}^{15}$. O diagnóstico correto da conjuntura por parte da autoridade monetária, que fundamenta as ações de política monetária, exige uma definição clara da situação, e os termos empregados refletem, ainda que imperfeitamente, os fenômenos considerados. A escolha dos termos não necessariamente exaure todos os conceitos que poderiam refletir as preocupações dos respectivos BCs sobre a evolução macroeconômica em um quadro de instabilidade financeira. Além disso, termos sinônimos podem ter sido discutidos e não captados pela análise. Contudo, os termos escolhidos fazem parte do vernáculo macroeconômico e são de uso disseminado na academia, no mercado financeiro e na imprensa especializada.

Desta forma, no caso do FOMC (Tabela 1), atividades especulativas estiveram presentes nas análises em todo o período, mas o potencial desestabilizador das mesmas não foi considerado. A instabilidade foi ignorada durante todo o período. Da mesma forma, a volatilidade financeira, característica intrínseca de uma economia financeirizada e mecanismo central em muitos desarranjos financeiros, só passa a ser considerada de forma mais frequente quando a bolha estoura. $\mathrm{O}$ setor imobiliário, que figura entre as preocupações dos BCs mesmo em períodos de estabilidade, ganhou maior importância nos anos próximos à crise. Ainda, a recessão só foi discutida após a economia passar a figurar oficialmente nesta situação. A possibilidade de uma desaceleração, sintomaticamente, não foi objeto de maior atenção por parte dos membros do FOMC. Já o declínio da atividade ganhou destaque apenas após o país entrar em recessão. Mas o aspecto mais importante é a ausência do termo 'bolha' durante todo o período, sendo mencionado uma única vez em 2010, apesar da ampla discussão acadêmica antes e durante a formação da bolha. Não surpreende, portanto, que a palavra "crise" só tenha sido discutida a partir de 2008. No período anterior, os BCs, se a interpretação da afirmação de Borio (2012) é correta, empregavam modelos sem finanças e, com base nos mesmos, discutiam apenas a grande moderação ${ }^{16}$, fenômeno incompatível com bolhas em preços de ativos e crises e pânicos financeiros.

O caso do Bacen apresenta os mesmos equívocos (Tabela 2). As atividades financeiras especulativas desaparecem da discussão entre 2007 e 2009, justamente

(15) Cabe notar que a regulação financeira também é importante na prevenção de crises, e as agências responsáveis por esta atividade, junto com o banco central, também deveriam ser consideradas. Mas em função do escopo deste trabalho, ficaram de fora da análise.

(16) Segundo Bernanke (2004), a grande moderação foi o período entre o final do século XX e início do século XXI, caracterizado pela redução da volatilidade macroeconômica. 
no auge do pânico e da crise financeira. Da mesma forma, o potencial desestabilizador não aparece em nenhuma reunião durante os oito anos, indicando que Minsky não é uma leitura apreciada no $\operatorname{Bacen}^{17}$. A questão da instabilidade é discutida pelo Copom com mais frequência no início do período, sugerindo dinâmicas domésticas próprias. Mas o termo perde intensidade até desaparecer após a eclosão da crise. A volatilidade financeira também segue o mesmo padrão, sendo cada vez menos discutida, até retomar importância em 2010 e 2011. Os termos associados ao epicentro da crise no setor imobiliário dos EUA ganham rápida importância durante o ápice da crise, para em seguida desaparecer. As hipotecas, instrumento pouco difundido no Brasil, também são discutidas com relação aos desdobramentos da crise nos EUA. A palavra recessão foi pouco discutida pelo Copom. Já a desaceleração, que se aplica a preços e valores, não apresenta uma evolução clara, sendo discutida de forma intensa durante todo o período, com exceção de 2011. Mesmo quando a economia brasileira se desacelera em 2009 o termo não ganhou maior ênfase. A redução do nível de atividade, dado o crescimento econômico experimentado pelo Brasil no período, foi pouco discutida e se tornou importante já em 2011, quando a taxa de crescimento do produto foi reduzida. Finalmente, da mesma forma que no FED, a existência de bolhas nos preços de ativos não figura no léxico das autoridades monetárias brasileiras, nem, segundo Borio (2012), em seus modelos macroeconômicos, apesar do aumento da frequência das bolhas e das crises financeiras nas últimas décadas.

Tabela 1

Frequência de utilização dos termos relacionados a crises nas atas do FOMC (2004 a 2011)

\begin{tabular}{l|c|c|c|c|c|c|c|c}
\hline Palavras-chave & 2004 & 2005 & 2006 & 2007 & 2008 & 2009 & 2010 & 2011 \\
\hline Speculation/Speculative & 8 & 9 & 9 & 15 & 12 & 21 & 11 & 16 \\
\hline Crisis/crises & 0 & 0 & 0 & 0 & 2 & 13 & 23 & 10 \\
\hline Instability & 1 & 0 & 0 & 0 & 0 & 1 & 0 & 0 \\
\hline Destabilizing & 0 & 0 & 0 & 0 & 0 & 0 & 0 & 0 \\
\hline Volatility & 1 & 2 & 1 & 8 & 6 & 11 & 15 & 14 \\
\hline Bubble & 0 & 0 & 0 & 0 & 0 & 0 & 1 & 0 \\
\hline Housing & 36 & 33 & 75 & 103 & 104 & 92 & 68 & 48 \\
\hline Real Estate & 4 & 7 & 4 & 8 & 12 & 28 & 42 & 32 \\
\hline Recession & 0 & 0 & 0 & 0 & 3 & 13 & 13 & 12 \\
\hline Slowdown & 7 & 4 & 9 & 7 & 9 & 4 & 5 & 9 \\
\hline Downturn & 2 & 1 & 3 & 3 & 9 & 9 & 8 & 3 \\
\hline
\end{tabular}

Fonte: Elaborada pelos autores, a partir da leitura das atas do FOMC no período de janeiro de 2004 a dezembro de 2011.

(17) De acordo com a revista The Economist (2010), o FED descobriu Minsky muito tarde, mas haveria uma incompatibilidade entre a visão do FED e a de Minsky sobre o funcionamento das economias capitalistas. Este é justamente o ponto. 
Tabela 2

Frequência de utilização dos termos relacionados a crises nas atas do Copom (2004 a 2011)

\begin{tabular}{l|c|c|c|c|c|c|c|c}
\hline Palavras-chave & 2004 & 2005 & 2006 & 2007 & 2008 & 2009 & 2010 & 2011 \\
\hline Especulação/especulativo(a) & 2 & 1 & 1 & 0 & 0 & 0 & 2 & 0 \\
\hline Crise & 6 & 0 & 2 & 15 & 40 & 40 & 58 & 36 \\
\hline Instabilidade & 8 & 3 & 5 & 2 & 1 & 0 & 0 & 7 \\
\hline Desestabilizador(a) & 0 & 0 & 0 & 0 & 0 & 0 & 0 & 0 \\
\hline Volatilidade & 36 & 37 & 28 & 27 & 15 & 5 & 26 & 36 \\
\hline Bolha & 0 & 0 & 0 & 0 & 0 & 0 & 0 & 0 \\
\hline Imóveis/Imobiliário & 1 & 2 & 4 & 23 & 18 & 6 & 2 & 0 \\
\hline Hipotecário/hipotecas & 0 & 0 & 0 & 9 & 18 & 0 & 2 & 1 \\
\hline Recessão & 0 & 0 & 3 & 2 & 7 & 5 & 0 & 2 \\
\hline Desaceleração & 57 & 87 & 45 & 48 & 86 & 67 & 43 & 63 \\
\hline Redução da atividade & 0 & 1 & 0 & 0 & 0 & 0 & 0 & 0 \\
\hline
\end{tabular}

Fonte: elaborada pelos autores, a partir da leitura das atas do Copom no período de janeiro de 2004 a dezembro de 2011.

Em resumo, se estes termos deveriam aparecer em um diagnóstico de uma profunda crise financeira, então as tabelas acima sugerem a existência de uma longa defasagem interna no que concerne ao diagnóstico correto da conjuntura macroeconômica, ao contrário do que convencionalmente se acredita sobre a política monetária. Sugere adicionalmente que os BCs têm uma reduzida capacidade de antecipação. Isto é ainda mais sintomático em termos da não incorporação dos eventos que conduzem a crises financeiras na operacionalização da política monetária em um contexto de crescente instabilidade financeira. Esta avaliação preliminar permite rejeitar a hipótese de que as autoridades monetárias podem não identificar os desequilíbrios financeiros a tempo de agir da melhor forma. Houve um lento processo de formação da bolha imobiliária e os desajustes foram observados pelo FED e pelo Bacen. A questão reside na incapacidade ou na falta de vontade do FED em atuar a partir desta identificação, o que os levou a ignorar a bolha e a subestimar a crise financeira.

A interpretação baseada em uma longa defasagem interna não exaure outras explicações, que podem complementá-la. Assim, uma outra possível explicação reside na discussão da economia política do $\mathrm{BC}$ e nas relações de classe que influenciam a política monetária, seguindo Kelton (2006) e Papadatos (2012), com os BCs deixando a bolha se formar e então socializando os prejuízos gerados pela crise. Neste caso a longa defasagem interna reside nos interesses que moldam a execução da política monetária. Da mesma forma, se a asserção de Borio (2012) na seção 1 estiver correta, uma terceira explicação possível estaria nos modelos macroeconômicos, em particular os modelos DSGE, em que o setor financeiro não desempenha qualquer papel relevante, ao mesmo tempo em que estes modelos diagnosticavam uma 'grande moderação' no período pré-crise financial global, 
mesmo com um aumento no número de episódios de crise desde os anos 1980. Sem um setor financeiro, não há como identificar bolhas financeiras de forma acurada, contribuindo para uma longa defasagem interna.

Uma quarta explicação estaria na crença na capacidade autorreguladora dos mercados financeiros frente a estes desequilíbrios, como ficou claro no testemunho de Alan Greenspan ao Congresso norte-americano, conforme exposto em Milan $(2012)^{18}$. Esta crença é igualmente compatível com a visão de Bernanke e Gertler (1999) de que um regime de metas de inflação agressivo faz com desequilíbrios financeiros sejam irrelevantes caso não afetem a trajetória da inflação. Por sua vez, a fé cega no livre mercado financeiro se fundamenta na hipótese dos mercados eficientes (HME). Jones (2015) resume algumas conclusões sobre o papel da HME e seus efeitos na crise. Retoma em primeiro lugar o testemunho acima de Greenspan e enfatiza a afirmação do mesmo de que o edifício intelectual da HME entrou em colapso. Cita texto de Paul Volcker sobre a fé irracional em expectativas racionais e mercados eficientes como causas da crise. Mostra como, para Krugman, a fé em mercados financeiros eficientes cegou os economistas para a maior bolha financeira - não diagnostica - da história. Por fim, resgata a avaliação de Grantham ${ }^{19}$. A afirmação sugere que a fé na HME leva à subestimação dos riscos de colapso das bolhas, o que é equivalente à uma defasagem interna longa.

Por fim, uma última explicação é fornecida por Bullio et al. (2011). Discutindo exclusivamente o papel do FED antes e depois da crise, os autores defendem que o FED foi leniente com a formação da bolha por acreditar que a elevação no preço dos imóveis ajudaria a mitigar os problemas financeiros associados ao estouro da bolha das empresas ponto-com, por acreditar nos benefícios da desregulamentação financeira (como na quarta explicação acima) e por priorizar a estabilidade de preços. Com a eclosão da crise, o FED abandonou a adesão a regras que fundamentam o receituário do Novo Consenso Macroeconômico e passou a operar de forma pragmática, ou seja, sem fundamentação teórica e discricionária, intervindo na economia enquanto emprestador de última instância à la Bagehot. Na mesma linha, Ferrara e Carvalho (2014) atribuem a leniência do FED à crença na resiliência do sistema financeiro norte-americano, à confiança na abordagem pragmática de gerenciamento de riscos da política monetária e à aceitação da

(18) O testemunho se deu na audiência do comitê de supervisão e reforma governamental da câmara dos deputados, em 23 de outubro de 2008. Greenspan admitiu ter tido muita fé no poder de autocorreção dos mercados e no autointeresse das instituições financeiras.

(19) "The incredibly inaccurate efficient market theory was believed in totality by many of our financial leaders, and believed in part by almost all. It left our economic and government establishment sitting by confidently, even as a lethally dangerous combination of asset bubbles, lax controls, pernicious incentives and wickedly complicated instruments led to our current plight. 'Surely, none of this could be happening in a rational, efficient world,' they seemed to be thinking. And the absolutely worst part of this belief set was that it led to a chronic underestimation of the dangers of asset bubbles breaking" (Jones, 2015, p. 19, n. 42). 
negligência benigna da política monetária atuando apenas após a bolha estourar. Os autores mostram que as autoridades monetárias identificaram os riscos mas preferiram não intervir, também em função das dificuldades impostas pela integração financeira global.

\section{Conclusão}

A literatura sobre política monetária, bolhas nos preços de ativos e crises financeiras não é conclusiva, mas sugere que há espaço para a incorporação da estabilidade financeira nas preocupações do BC. A visão mainstream, ainda que diversa, é mais reticente com relação a esta possibilidade. A visão heterodoxa, ainda mais heterogênea, mesmo que não tenha desenvolvido formalmente um arcabouço para avaliar a questão, desloca-a para o âmbito da regulação temporária dos mercados financeiros, para os interesses de classe subjacentes ao regime de metas de inflação e mesmo para a incapacidade de antecipação das autoridades monetárias em função da incerteza fundamental. Do ponto de vista empírico, a análise das atas das reuniões dos $\mathrm{BCs}$ permite concluir que o FED tinha percebido um crescimento incomum nos preços dos imóveis, porém subestimou os impactos dessa evolução, como mostra a declaração de Bernanke de que não havia uma bolha no setor imobiliário no auge da mesma. Assim, certamente não se poderiam implementar ações apropriadas. Como o FED não reagiu às elevações nos preços e só identificou tardiamente os desequilíbrios financeiros ocasionados pelo estouro da bolha, não se pode rejeitar a caracterização, com base neste episódio, de que as autoridades monetárias podem não ser capazes de identificar os desequilíbrios financeiros com suficiente antecedência, levantando dúvidas sobre o comportamento forwardlooking. Isto não é surpreendente, dada a inexistência do setor financeiro nos modelos macroeconômicos empregados por esta instituição, ao mesmo tempo em que se assume a HME, e também em razão de o regime de metas de inflação implícito no caso do FED, como já mencionado anteriormente, em função do mandato dual para estabilizar o nível de preços e assegurar o pleno emprego - impor inúmeras restrições à capacidade de reação do $\mathrm{BC}$ à instabilidade financeira. Já o Bacen não percebeu o crescimento especulativo nos preços dos imóveis nos EUA e acreditava na resiliência financeira da economia norte-americana, sugerindo uma fé parecida na HME. Quando os primeiros sinais de crise foram vistos, a instituição assumia que os problemas não seriam tão sérios para a economia mundial, subestimando os efeitos da crise. Em meio ao colapso financeiro global, o Bacen implementou uma política de aperto monetário. Se o Bacen opera com base na evolução macroeconômica futura, isto é, ele se antecipa por ter comportamento forward-looking, como suposto na abordagem mainstream padrão, esta política de aperto sugere que o mesmo esperava uma rápida recuperação e riscos elevados de inflação nos próximos meses, uma leitura que se mostrou equivocada. O mais provável é que o Bacen agiu com base nos eventos imediatos de curto prazo ou 
mesmo a pressões do mercado financeiro, como sugere a economia política dos bancos centrais.

Estes resultados reforçam a percepção de que há espaços importantes para a mudança na forma de governança dos BCs e de implementação da política monetária e de estabilização financeira. O regime de metas de inflação subordina todos os objetivos da política monetária à estabilidade de preços e os modelos macroeconômicos convencionais não possuem papel para o setor financeiro de forma séria, isto é, não reduzido a simples "fricções". A elevada frequência de episódios de crises financeiras pode ser explicada em termos da mudança de orientação dos BCs desde a década de 1990, quando passam a se guiar por estes modelos e a adotar, em muitos casos, regimes de metas de inflação. O mainstream, na medida em que reconhece pelo menos parcialmente o problema da instabilidade financeira, mas o subordina à estabilidade de preços dentro do paradigma dos microfundamentos neoclássicos da macroeconomia, não representa uma alternativa promissora. O esforço da Brookings Institution em repensar a atividade dos BCs é evidência deste desconforto. Por sua vez, a abordagem heterodoxa, ainda que não constitua um corpo coeso e único de conhecimento, possui os instrumentos necessários para elaborar políticas monetárias e de regulação financeira mais consistentes com o crescimento econômico, inflação sob controle e estabilidade financeira. Mas ainda não possui uma articulação das principais contribuições sobre as relações entre política monetária, interesses de classe e crises financeiras. Ou seja, a perspectiva heterodoxa precisa estabelecer um arcabouço teórico que trate da formação de bolhas e do papel da política monetária, tal como existente hoje, moldada por fortes interesses financeiros, e não apenas como o desideratum normativo de uma possível modificação das funções institucionais do BC. A crise de 2007-2008 e a estagnação das economias capitalistas avançadas que se seguiu representam uma oportunidade para avançar esta agenda, mostrando que os BCs têm muita dificuldade de efetivamente se antecipar aos eventos futuros próximos e distantes, mas isto não quer dizer que nada possa ser feito a respeito da instabilidade financeira das economias capitalistas.

\section{Bibliografia}

ARESTIS, P.; SAWYER, M. The political economy of Central Banking. Cheltenham: Edward Elgar, 1998.

BAIN, K.; HOWELLS, P. Monetary economics - Policy and its theoretical basis. New York: Palgrave MacMillan, 2003.

BAKER, D. Plunder and blunder - The rise and fall of the bubble economy. Sausalito: PoliPointPress, 2009.

BANCO CENTRAL DO BRASIL. Atas do Copom. Diversos anos. 
BERNANKE, B. The great moderation. Remarks by Governor Ben S. Bernanke at the meetings of the Eastern Economic Association, Washington, DC, Feb. 20. Disponível em: http://www.federalreserve.gov/BOARDDOCS/SPEECHES/2004/ 20040220/default.htm Acesso em 20/06/215.

BERNANKE, B.; GERTLER, M. Monetary policy and asset price volatility. Economic Review, Federal Reserve Bank of Kansas City, p. 17-51, 4 Quarter 1999.

BLANCHARD, O. Monetary policy in the wake of the crisis. In: IMF CONFERENCE ON MACRO AND GROWTH POLICIES IN THE WAKE OF THE CRISIS, Washington DC, Mar. 7-8, 2011.

BLINDER, A. The case against the case against discretionary fiscal policy. Center for Economic Policy, Princeton University, 2004. (Studies Working Paper, n. 100).

BORDO, M.; JEANNE, O. Monetary policy and asset prices: does "benign neglect" make sense? International Finance, v. 5, n. 2, p. 139-164, Feb. 2002.

BORIO, C. The financial cycle and macroeconomics: what have we learnt? Basel, Switzerland: BIS, 2012. (Working Papers, n. 395).

BORIO, C.; LOWE, P. Imbalances or "bubbles"? Implications for monetary and financial stability. In: HUNTER, W. C.; KAUFMAN, G. G.; POMERLEANO, M. (2005, p. 247-275).

BRESSER-PEREIRA, L. C. The 2008 financial crisis and neoclassical economics. Revista de Economia Política, São Paulo, v. 30, n.1, p. 3-26, Mar. 2010.

BULliO, O.; FERRARA, D. N.; CUNHA, P.; CARVALHO, C. E. A atuação do Fed antes e depois do estouro da bolha imobiliária: discricionariedade e mandato de bancos centrais em contexto de desregulamentação financeira. Economia $e$ Sociedade, Campinas, v. 20, n. 2 (42), p. 329-364, ago. 2011.

CARLIN, W.; SOSKICE; D. The 3-equation new Keynesian model: a graphical exposition. The B. E. Journal of Macroeconomics, v. 5, n. 1, p. 1-38., 2005.

CECCHETTI, S. G. Monetary policy and the financial crisis of 2007-2008. Centre for Economic Policy Research. 2008. (Policy insight, n. 21). Disponível em: http://www.cepr.org/pubs/policyinsights/PolicyInsight21.pdf. Acesso em: 20 out. 2013.

CECCHETTI, S. G.; GENBERG, H.; WADHWANI, S. Asset prices in a flexible inflation targeting framework. In: HUNTER, W. C.; KAUFMAN, G. G. POMERLEANO, M. (2005, p. 459-463).

DEUTSCHE BANK. Bank performance in the US and Europe: An ocean apart. Current issues, global financial markets. 2013. Disponível em: http://www.dbresearch.com/PROD/DBR_INTERNET_EN-PROD/PROD000000 
0000320825/Bank+performance+in+the+US+and+Europe\%3A+An+ocean+apart. pdf. Acesso em: 20 out. 2013.

DULLIEN, S. Is new always better than old? On the treatment of fiscal policy in Keynesian models. Review of Keynesian Economics, Inaugural Issue, p. 5-23, Autumn 2012.

EICHENGREEN, B. et al. Rethinking central banking. Washington, DC: Brookings Institution, 2011.

EPSTEIN, G. Political economy and comparative Central Banking. Review of Radical Political Economics, v. 24, p. 1-30, Spring 1992.

EPSTEIN, G. Financialization, rentier interests, and Central Bank Policy, 2002. Disponível em: http://www.peri.umass.edu/fileadmin/pdf/financial/fin_Epstein.pdf. Acesso em: 20 out. 2013.

FEDERAL RESERVE BOARD. Minutes of FOMC Meeting. Vários anos.

FEDERAL RESERVE BOARD. Meeting transcripts. Dec. 2007. Disponível em: http://www.federalreserve.gov/monetarypolicy/files/FOMC20071211meeting.pdf.

Acesso em: 20 out. 2013.

FERRARA, D. N.; CARVALHO, C. E. O Fed antes da crise: erros de percepção ou de concepção? análise das atas do FOMC e de falas de Greenspan e de Bernanke de 2001 a 2007. Economia e Sociedade, Campinas, v. 23, n. 3 (52), p. 757-792, dez. 2014.

FRIEDMAN, B. M. Comments on implications of bubbles for monetary policy. In: HUNTER, W. C.; KAUFMAN, G. G.; POMERLEANO, M. (2005, p. 459-463).

FRIEDMAN, B. M. A monetary and fiscal framework for economic stability. The American Economic Review, v. 38, n. 3, p. 245-264, Jun. 1948.

FRIEDMAN, B. M. A program for monetary stability. New York: Fordham University Press, 1960.

GNOS, C.; ROCHON, L-P. Monetary policy and financial stability - A post Keynesian agenda. Cheltenham, UK: Edward Elgar, 2009.

GOODFRIEND, M. Interest rate policy should not react directly to asset prices. In: HUNTER, W. C.; KAUFMAN, G. G.; POMERLEANO, M. (2005, p. 445-457).

HENDERSON, N. Bernanke: There's no housing bubble to go bust. Washington Post, Washington, 27 Oct. 2005. Disponível em: http://www.washingtonpost. com/wp-dyn/content/article/2005/10/26/AR2005102602255.html Acesso em: 20 out. 2013. 
HUNTER, W. C.; KAUFMAN, G. G.; POMERLEANO, M. Asset price bubbles: the implications for monetary, regulatory, and international policies. Cambridge: The MIT Press, 2005.

ITO, T. Looking forward on monetary and supervision policies to protect against bubbles. In: HUNTER, W. C.; KAUFMAN, G. G.; POMERLEANO, M. (2005, p. 547-552).

JONES, B. Asset bubbles: re-thinking policy for the age of asset management. Washington, DC: IMF, 2015. (Working Paper, n. 15/27).

KELTON, S. Behind closed doors: the political economy of Central Banking in the United States. International Journal of Political Economy, v. 35, n. 1, p. 5-23, 2006.

MESQUITA, M.; TORÓS, M. Considerações sobre a atuação do Banco Central na crise de 2008. Brasília: Banco Central do Brasil, mar. 2010. (Trabalhos para Discussão, n. 202).

MILAN, M. A Crise financeira nos EUA: causas, consequências e desdobramentos teóricos. Revista da Sociedade Brasileira de Economia Política, n. 33, p. 103-145, 2012.

MINSKY, H. P. John Maynard Keynes. New York: Columbia University Press, 1975.

MINSKY, H. P. The financial instability hypothesis: capitalist processes and the behavior of the economy. In: KINDLEBERGER, Charles P.; LAFFARGUE, JeanPierre (Ed.). Financial crises - Theory, history \& policy. Cambridge, MA: Cambridge University Press, 1979.

MINSKY, H. P. (1957). Central Banking and money market changes. In: MINSKY, Hyman. Can "it" happen again? Essays on instability and finance. Armonk, New York: ME Sharpe, 1982.

MINSKY, H. P. (1986). Stabilizing an unstable economy. New York: McGrallHill, 2008.

MISHKIN, F. S.; WHITE, E. N. U.S. stock market crashes and their aftermath: implications for monetary policy. In: HUNTER, W. C.; KAUFMAN, G. G.; POMERLEANO, M. (2005, p. 53-79).

MISHKIN, F. S. Monetary policy strategy. Cambrigde, MA: MIT Press, 2007.

MORETTI, F.; PRESQUE, D. Bankspeak: the language of World Bank reports. New Left Review, n. 92, p. 75-99, Mar./Apr. 2015.

MUSSA, M. Asset prices and monetary policy. In: HUNTER, W. C.; KAUFMAN, G. G.; POMERLEANO, M. (2005, p. 41-50). 
OECD. Annual Report. Paris, 2009.

PALLEY, T. Asset price bubbles and the case for asset based reserve requirements. Challenge, n. 46, p. 53-72, May/Jun. 2003.

PALLEY, T. A post Keynesian framework for monetary policy: why interest rate operating procedures are not enough. In: GNOS, C.; ROCHON, L.-P. (Ed.). Post Keynesian principles of policy. Cheltenham: Edward Elgar, 2006.

PALLEY, T. Monetary policy and Central Banking after the crisis: the implications of rethinking macroeconomic theory, 2011. (IMK Working Paper, n. 08). In: EPSTEIN, Gerald; WOLFSON, Martin (Ed.). The Handbook on Political Economy of Financial Crises. Oxford: Oxford University Press. Disponível em: http://www.utexas.edu/lbj/sites/default/files/file/news/Monetary\%20Policy\%20Aft er\%20Crisis\%20-rethinking\%20macroeconomic\%20theory.pdf. Acesso em: 21 out. 2013.

PAPADATOS, D. Central Banking in contemporary capitalism: inflation-targeting and financial crises. In: LAPAVITSAS, Costas (Ed.). Financialisation in crisis. Leiden: Brill, 2012.

RITHOLTZ, B. Laughing along with the Fed: Ritholtz Chart. Disponível em: http://www.bloombergview.com/articles/2014-02-24/laughing-along-with-the-fedritholtz-chart. Acesso em: 25 fev. 2014.

ROUSSEAS, S. Post Keynesian monetary economics. 3. ed. Basingstoke, Hampshire: Palgrave Macmillan, 1998.

SICSÚ, J. O conceito de normalidade econômica marshalliano e o discricionarismo monetário de Keynes. Nova Economia, v. 9, n. 1, p. 153-170, jul. 1999.

THE ECONOMIST. The Fed discovers Hyman Minsky. Jan. 7, 2010. Disponível em: http://www.economist.com/blogs/freeexchange/2010/01/the fed discovers hyman minsky. Acesso em: 20 out. 2013.

TRICHET, J-C. Asset price bubbles and their implications for monetary policy and financial stability. In: HUNTER, Willian C; KAUFMAN, George G.; POMERLEANO, Michael (2005, p. 15-22).

TYMOIGNE, E. Central Banking, asset prices and financial fragility. New York: Routledge, 2009. 